\title{
THE STUDY OF MODERN HYBRIDS OF GRAIN SORGHUM IN THE CONDITIONS OF THE STEPPE ZONE
}

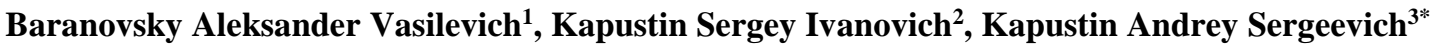 \\ ${ }^{1}$ Lugansk National Agrarian University, the town LNAU, 1, Lugansk, 91008, Ukraine; \\ ${ }^{2}$ North Caucasus Federal Agricultural Research Center, Nikonov str. 49, Mikhailovsk, Stavropol region, 356241, \\ Russia; \\ ${ }^{3 *}$ North Caucasus Federal University, Pushkin str. 1, Stavropol, 355017, Russia; \\ *Corresponding Author Kapustin Andrey Sergeevich, e-mail: hpplus@bk.ru;
}

Received June 2019; Accepted August 2019; Published October 2019;

DOI: https://doi.org/10.31407/ijees9417

\begin{abstract}
In modern conditions of global climate change towards warming, in order to guarantee the provision of an increasing population of the planet with food, and especially grain, the issue of selecting the most productive, drought-resistant and heat-resistant crops becomes very urgent. One of such promising plants is sorghum grain, the main products of which are used for food, fodder and technical purposes. Almost every year, this crop in the steppe arid regions significantly exceeds traditional spring crops - oats, barley, corn and millet. In the State Register of Breeding Achievements Approved for Use in Russia for 2019, 120 domestic and foreign varieties and hybrids of grain sorghum were registered. The purpose of the research is to study the productivity of modern hybrids of sorghum grain in the soil and climatic conditions of the steppe zone on the basis of the Lugansk National Agrarian University in the crop rotation of the Department of Agriculture and Environmental Ecology (2016-2018). As a result of the studies, the most productive and maximally adapted crop varieties were established, which have the highest manufacturability and guaranteed maturation by the end of the growing season. In all the studied hybrids, no shedding of grain from panicles was recorded, even when the plants were stopped. The greatest damage to the leaves of cereal aphids was found in the wetter 2016. The average productivity of grain sorghum in the favorable year was $6.2 \mathrm{t} / \mathrm{ha}$, in the arid year $2018-5.01 \mathrm{t} / \mathrm{ha}$. On average, in 2016-2018, the highest yields (over $6.0 \mathrm{t} /$ ha of grain) were obtained for early-ripening hybrids Frisket and PR88Y20 and mid-early Puma Star, Solarius and Bianka. These developments can be successfully implemented in agricultural production of the steppe regions of the North Caucasus region.
\end{abstract}

Key words: grain sorghum, soil and climatic conditions, phenology, grain yield, yield structure indicators. 